\title{
Risk of Misinforming and Message Customization in Customer Relationship Management
}

\author{
Dimitar Christozov \\ American University in Bulgaria, \\ Blagoevgrad, Bulgaria \\ dgc@aubg.bg
}

\author{
Stefanka Chukova \\ Victoria University of \\ Wellington, New Zealand \\ stefanka.chukova@vuw.ac.nz
}

\author{
Plamen Mateev \\ Sofia University “St. Kliment Ohridski”, Sofia, Bulgaria \\ pmat@fmi.uni-sofia.bg
}

Abstract

This paper discusses applications of the measures of the risk of misinforming and the role of the warranty of misinforming in the context of the informing component of Customer Relationship Management (CRM) issues. This study consists of two parts. Firstly, we propose an approach for customers' grouping based on their attitude toward assessing product's properties and their expertise on the terminology/domain of the seller's message describing the product. Also we discuss what the most appropriate personal/group warranty is for each of these group/clusters.

Key words: measures of the risk of misinforming, warranty of misinforming, customer related management, customer's purchase attitude, customers expertize.

\section{Introduction}

"Half the money I spend on advertising is wasted; the trouble is I don't know which half." John Wanamaker (1838-1922)

Customer related management is an established practice allowing a company to relate directly to its customers by addressing them as independent individuals via maintaining customers' profiles. The current computer and communication technologies (CCT) provide tools that allow one to avoid sales mediators and also allow producers to collect the first-hand information related to end-users' attitude during the process of purchasing and acquiring a new product. CCT allows companies to customize their products so that any particular customer receives individualized

Material published as part of this publication, either on-line or in print, is copyrighted by the Informing Science Institute. Permission to make digital or paper copy of part or all of these works for personal or classroom use is granted without fee provided that the copies are not made or distributed for profit or commercial advantage AND that copies 1) bear this notice in full and 2) give the full citation on the first page. It is permissible to abstract these works so long as credit is given. To copy in all other cases or to republish or to post on a server or to redistribute to lists requires specific permission and payment of a fee. Contact Publisher@InformingScience.org to request redistribution permission. targeted service. Regardless of the opportunities provided by CCT, the usual practice nowadays continuous to be to address all customers with a unified message. In this paper we consider the problem of seller generating customized messages to potential customers, based on their profiles, and offering personalized/group warranty aiming to encourage product trials and sales. 
Customizing the message allows mitigation of the risk of wrong interpretation of the message by the customer within his or her problem domain. The risk of this wrong interpretation is the risk of misinforming. In this paper we distinguish these interpretations: (1) "informing", when a message developed by the sender is conveyed correctly and understood and interpreted correctly by the receiver in the way intended by the sender; (2) "disinforming", when the sender provides intentionally incorrect information aiming to mislead the receiver; and (3) "misinforming", when the sender's message consisting the correct and complete information is misunderstood and interpreted incorrectly by the receiver, which results in misinterpretation of the information.

The product warranty, offered by the seller/producer, could provide coverage for two types of hazards that the customer may encounter while purchasing and acquiring a new product. The first one is related to the malfunctioning of the product, i.e., the product does not function according to its specifications. In this case, the product is repaired or replaced with no charge to the customer. The second issue is related to customer's satisfaction, i.e., to what extent the product meets the customer's expectations to solve for her problems/tasks. In other words, to what extent, at the time of the purchase, the customer has been correctly informed regarding the product capability to solve her problems/tasks and to satisfy her needs. The warranty that provides coverage against the second issue is called "warranty of misinforming". If the customer is not "fully satisfied", the warranty of misinforming allows for the return of the product. The warranty of misinforming provides an opportunity for the customer to explore and learn more about the properties and features of the product without incurring any risk.

The risk of misinforming is caused by the information asymmetry between sellers and customers. The phenomenon of information asymmetry between two parties occurs when one of the parties has better understanding, that is, has broader and deeper knowledge on the subject of communication, than the other one. For example, a car dealer is an expert on the performance of his products and possesses complete information on all features and qualities of the product, such as reliability, performance, and purchase contract parameters. On the other hand, an average customer might be quite well informed about the product she is interested in buying, but her overall knowledge of the particular vehicle is, generally, limited compared to the knowledge of her counterpart in the sale/purchase process. Consider another example; assume that a customer purchases a new product, e.g., a new personal computer (PC). The purchase is made in order to address some particular needs and to perform for a particular set of the customer's tasks, e.g., to develop text documents, to make simple or complex calculations, to send and receive e-mails, to browse Internet, to play games or listen to music and watch movies. The PC has particular characteristics (specifications), such as CPU speed, memory capacity, etc., which allow the customer to execute her tasks. So, should "one for all customers" message, describing the product be provided or is a personal/group product message preferable so to stimulate the sales among "similar" customers?

Several studies in the last decade (see Christozov, Chukova, \& Mateev, 2014) address the risk of misinforming in the case of a single message distributed among a group of potential customers aiming to support their purchase decision process and the role of warranty in this process. In particular, Christozov, Chukova, \& Mateev (2009) consider the marketplace as a place where messages, describing different products suitable for solving one and the same set of customers' tasks, are competing, and discuss the evaluation of the risk for multiple competing offers. In the current study we consider in some way the reverse situation: we study one and the same product, say $\boldsymbol{D}$ that has to be described by different messages addressing different groups of potential customers, distinguished by their purchase attitude and domain expertise.

This paper addresses the following problem: how the measures of the risk of misinforming and customers' attitude toward messages describing product $\mathbf{D}$ can be utilized for message customization for CRM purposes. In this paper we focus on two issues - exploring customers' expertise related to the product domain, measured by the value of the information asymmetry 
$i a_{j}=a \quad\left(\quad p_{p}-\hat{p}_{i j}\right)^{1}$ and customers' attitude toward purchasing products under uncertainty. Based on their purchase attitude the customers are classified as (1) optimists - they are incline to overestimate the product's quality $\sum_{i=1}^{k} n_{i j}\left(\hat{p}_{i j}-p_{i}\right)>\varepsilon$, (2) pessimists - inclined to underestimate product quality $\sum_{i=1}^{k} n_{i j}\left(\hat{p}_{i j}-p_{i}\right)<-\varepsilon$ and (3) realists - they access relatively (within acceptable limits) correctly the product quality. The optimists tend to purchase the product even when it is not entirely suitable for their needs; the pessimists are very cautious and often do not purchase a product that fully meets their needs.

The paper is organized as follows. We start with a review of related works. Next, we introduce the measures for customers' attitude in assessing product's quality and customer's domain expertise as a function of their response to the seller's message. Further we propose a distance, which allows clustering of customers' population according to their attitude and expertise. In conclusion we summarize the contribution of this work and outline some directions of further research.

\section{Related Works}

\section{Information Asymmetry}

The concept of information imbalance originates in Arrow (1963/2001). His ideas were further developed by Akerlof (1970) in his famous paper "The Market for "Lemons", where the term "information asymmetry" was firstly introduced. Akerlof investigated the influence of asymmetric information on the market value of a commodity and his ideas initiated studies on the impact and usage of the information asymmetry to improve the influence in business relationships. Slovac (1993) studied the asymmetric impact of negative and positive information on the social trust, known as principle of Information Asymmetry or Trust Asymmetry. White and Eiser (2005) continue this line of research. The role of information asymmetry as a source of misinterpretation, which results in misinforming and/or misleading in a sales/purchase process and might lead to wrong purchase decisions, hasn't been studied at the level it deserves. Some authors (Hsieh, Lai, $\&$ Shi, 2006) consider the impact of information asymmetry on the success in business transactions, but they do not go beyond recommendations on how to improve the information process. Christozov, Chukova, \& Mateev (2006) proposed a model to quantify the risk of misinforming caused by information asymmetry and its impact on warranty, which was further elaborated in a series of papers. The current paper extends this line of study.

\section{Warranty and CRM}

Huang, Lin, and Ho (2013) consider production systems with inspections, to ensure that the performance of a sold product satisfies the customer requirements. Nevertheless, some defective products may still be sold in practice. In such a case, warranties are essential in marketing products and can improve the unfavourable image by applying higher product quality and better customer service. The purpose of their study is to provide manufacturers with an effective inspection strategy in which the task of quality management is performed under the considerations of related costs for production, sampling, inventory, and warranty. In González-Prida, Gómez, Barberá, and Crespo (2012), the authors present and develop the Customer Relationship Management (CRM) stage for the improvement of the warranty management, and show how it can help the decision-

\footnotetext{
${ }^{1}$ Here we use Christozov, Chukova, \& Mateev (2011) notations (see the Appendix)
} 
making related to some aspect of the warranty management in the distribution network service providers (DNSP) sector. González Díaz, Barberá Martínez, Gómez Fernández, and Crespo Márquez, A.,(2012) propose a reference framework for the management of warranty - Warranty Program Improvement, which includes the implementation of new technologies, the Customer Relationship Management as well as the Six Sigma methodology. In Bella, Ferri, Hernández-Orallo, and Ramírez-Quintana (2009), taxonomy of CRM problems is given, and some open problems are formulated including the purchase probability rankings problem.

\section{Measures for Customers' Assessing Attitude and Domain Expertise}

Let us assume that there is one-to-one correspondence between a property or a characteristic $\left\{a_{i}^{c}, i=1,2, \ldots \mathrm{k}\right\}$ of the product $\boldsymbol{D}$ and a category of tasks $\left\{a_{i}^{p}\right\}$ customers are looking to solve by using the product $\boldsymbol{D}$. Also, let us assume that each property of $\mathrm{D}$ is described $\left\{a_{i}^{d}\right\}$ by a separate part of the seller's message. Onwards we will use a single notation $a_{i}$ to denote all of the above the product characteristics, the customer category of tasks and the related part of the seller's message. Thus, the expertise and attitude of a customer towards the product is measured by how she interprets the product's quality associated to her problem as described in the related part of the message.

\section{Measure of Attitude}

Christozov, Chukova, and Mateev (2007) suggested three categories of customers' attitudes while making purchase decisions - optimists, realists, and pessimists - based on whether customers are inclined to overestimate, estimate correctly, or underestimate product's properties. In general those three sets are not clearly distinguishable and using the proposed $\varepsilon$-definition is difficult to implement in practice. Instead, we can measure customers' attitude by the difference between the actual value of product's properties and the value as it is assessed by the customer, based on her interpretation of the seller's message. The customer attitude is measured by the weighted sum across all of the problems the product is intended to solve, where the weights are equal to the customer's needs (or customer's utility):

$$
C_{j}^{A}=\frac{1}{\sum_{i=1}^{k} n_{i j}} \sum_{i=1}^{k} n_{i j}\left(\hat{p}_{i j}-p_{i}\right),
$$

where $n_{i j}$ is the need of customer $b_{j}$ in using property $a_{i} ; p_{i}$ is the actual value of the property $a_{i}$, measured as the probability that the product $\boldsymbol{D}$ is able to solve customer's problem $a_{i} ; \hat{p}_{i j}$ is the customer $b_{j}$ 's assessment of the probability that the product is able to solve her problems related to property $a_{i}$ based on the provided message. A negative value of $C_{j}^{A}$ refers to the class of pessimists, a positive value - to the class of optimists. Values of $C_{j}^{A}$ that is close to zero describes a customer-realist, i.e., a customer with realistic assessment of the properties of the product.

The proposed measure suffers from the typical aggregation problem when "optimistic" attitude toward one property is compensated by "pessimistic" attitude toward another. Weighted by needs aggregation, assumes that attitude toward the most needed properties dominate the overall attitude. 
Another possible approach of constructing a measure of customer's attitude is instead of a scalar measure $C_{j}^{A}$ of customer attitude, to use $C_{j}^{A^{*}}=\left\{\left(\hat{p}_{1 j}-p_{1}\right),\left(\hat{p}_{2 j}-p_{2}\right), \ldots,\left(\hat{p}_{k j}-p_{k}\right)\right\}$, which is a vector of dimension $k$ measuring the customer attitudes toward each of the product's properties described in the message. Therefore there are two possible approaches to measure the customer's attitude - an "aggregated" approach or "distributed" approach.

\section{Measure of Expertise}

In our modeling the customer expertise is expressed mainly by $\hat{p}_{i j}$ - the customer $b_{j}$ estimation on the product suitability for solving her task related to property $a_{i}$ based on the provided message. So, there are two viewpoints regarding the properties of product $\boldsymbol{D}$ - the true suitability $p_{i}$ of the product regarding task $a_{i}$ and estimated by customer $b_{j}$ suitability $\hat{p}_{i j}$ of the product regarding task $a_{i}$. Based on these two viewpoints regarding the suitability of the product, we construct appropriately two probability distributions and use the Kullback - Leibler (see Kullback and Leibler, 1951) divergence (KL divergence) between these two distributions to measure the customers' level of expertise.

Let us denote the probability that customer $b_{j}$ has to solve task $a_{i}$ as $\frac{n_{i j}}{n_{. j}}$, where $n_{. j}=\sum_{i=1}^{k_{j}} n_{i j}$ or $n_{. j}$ is the total need for all tasks customer $b_{j}$ needs to solve with $\boldsymbol{D}$. Then, the probability that task $a_{i}$ has to be solved by customer $b_{j}$ and she will be able to solve it with $\boldsymbol{D}$ is $p(i \mid j)=P_{i j}=$ $p_{i} \frac{n_{i j}}{n_{. j}} \geq 0$. We can apply this idea to the entire set of tasks that $\boldsymbol{D}$ is supposed to solve, having in mind that a particular customer $b_{j}$ doesn't need to solve some of those problems and for them corresponding $n_{i j}=0$ and related probability is also zero. Therefore $\sum_{i=1}^{k} P_{i j} \leq 1$, and it is equal to 1 if and only if $p_{i}=1$, for all $i$. Let's denote by $P_{o j}=1-\sum_{i=1}^{k} P_{i j} \leq 1$ the complemented probability and then

$$
P_{j}=\left\{P_{o j}, P_{1 j}, \ldots, P_{k j}\right\}
$$

represents the "true" probability distribution characterizing the suitability of $\boldsymbol{D}$ regarding the categories of tasks adjusted to the customer $b_{j}$ needs. If we use $\hat{p}_{i j}$ instead of $p_{i}$, we can construct the "estimated" probability distribution characterizing the suitability of $\boldsymbol{D}$ regarding the categories of tasks adjusted to the customer $b_{j}$ needs

$$
\hat{P}_{j}=\left\{\hat{P}_{o j}, \hat{P}_{1 j}, \ldots, \hat{P}_{k j}\right\} .
$$

Then the measure of expertise of customer $b_{j}$ is given by

$$
C_{j}^{E}=\sum_{i=1}^{k} P_{i j} \log \frac{P_{i j}}{\hat{P}_{i j}} .
$$

\section{Clustering of Customers}

\section{Distance}

We will use the measures of attitude and expertise from the customer's profile to define a distance. This distance will split the customer's population into groups: with high similarity for customers within a group and high difference for customers in different groups. This is a typical cluster analysis problem. To illustrate the proposed approach we will use the aggregated measure of attitude and the measure of expertise. In this way, every customer can be represented as a point in a two-dimensional XY-plane as in Figure 1, where coordinates are her measures for attitude 
and expertise. Four categories of customers, which can be naturally distinguished, are Realistsexperts; Pessimists-non Experts, Optimists-non Experts, and customers with rational behavior who are not experts, and overestimate some of the properties of the product and underestimate other.

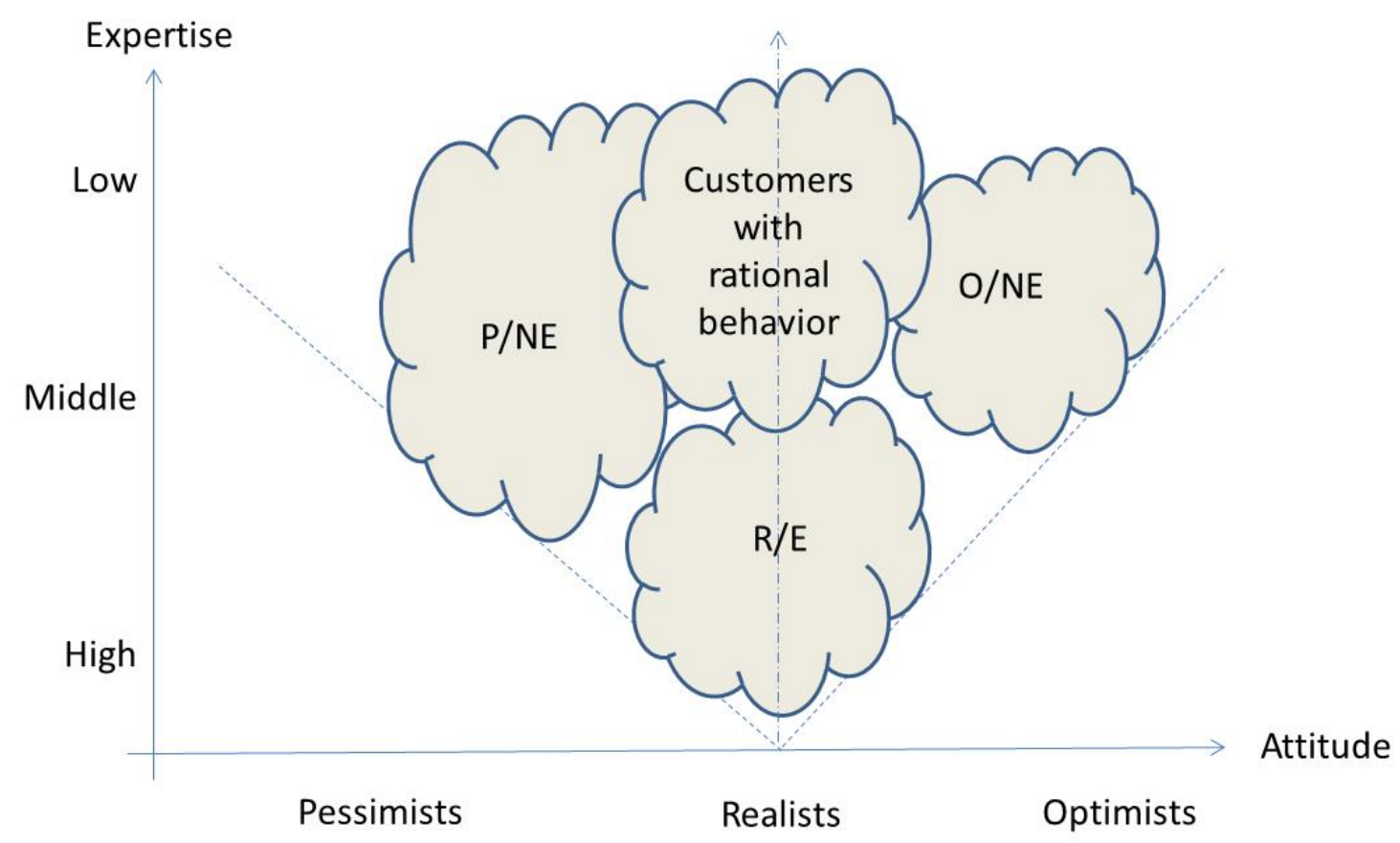

Figure 1. Clustering population of customers in Attitude/Expertise plane

Our goal is to form clusters (groups) of customers based on their purchase attitude and domain expertise related to the product offered. We will use these clusters to design a specific message conveying the offer, customized to address the specifics of the group. The partitioning/clustering of the customers' population is based on the following two factors - purchasing attitude and domain expertise as described above.

The aggregated measure of purchasing attitude allows us to assign to customer $b_{j}$ a value of $x_{j}$, such that

$$
x_{j}=\frac{1}{\sum_{i=1}^{k} n_{i j}} \sum_{i=1}^{k} n_{i j}\left(\hat{p}_{i j}-p_{i}\right),
$$

which varies within the interval $\left[\min _{i}\left(\hat{p}_{i j}-p_{i}\right), \max _{i}\left(\hat{p}_{i j}-p_{i}\right)\right]$. To measure the domain expertise of $b_{j}$ customer we use the KL divergence as follows:

$$
y_{j}=\sum_{i=1}^{k} P_{i j} \log \frac{P_{i j}}{\hat{P}_{i j}} .
$$

Therefore, for each customer $b_{j}$, using the above two factors, we are able to assign a point $B_{j}=\left(x_{j}, y_{j}\right)$ on the XY-plane. Hence, we are able to represent the group of customers as a set of points on the two-dimensional XY-plane. For example, the points representing customers who were classified as realists should be located somewhere close to the origin (according to the atti- 
tude) and their $y_{j}$ value (domain expertise) should be also close to zero. The main idea is that customers with similar expertise and similar purchase attitude have to be addressed by similar message describing the product, i.e., we need to define the notion of "close" points and adjust the message to reduce the risk of misinforming as much as possible for these "close" points.

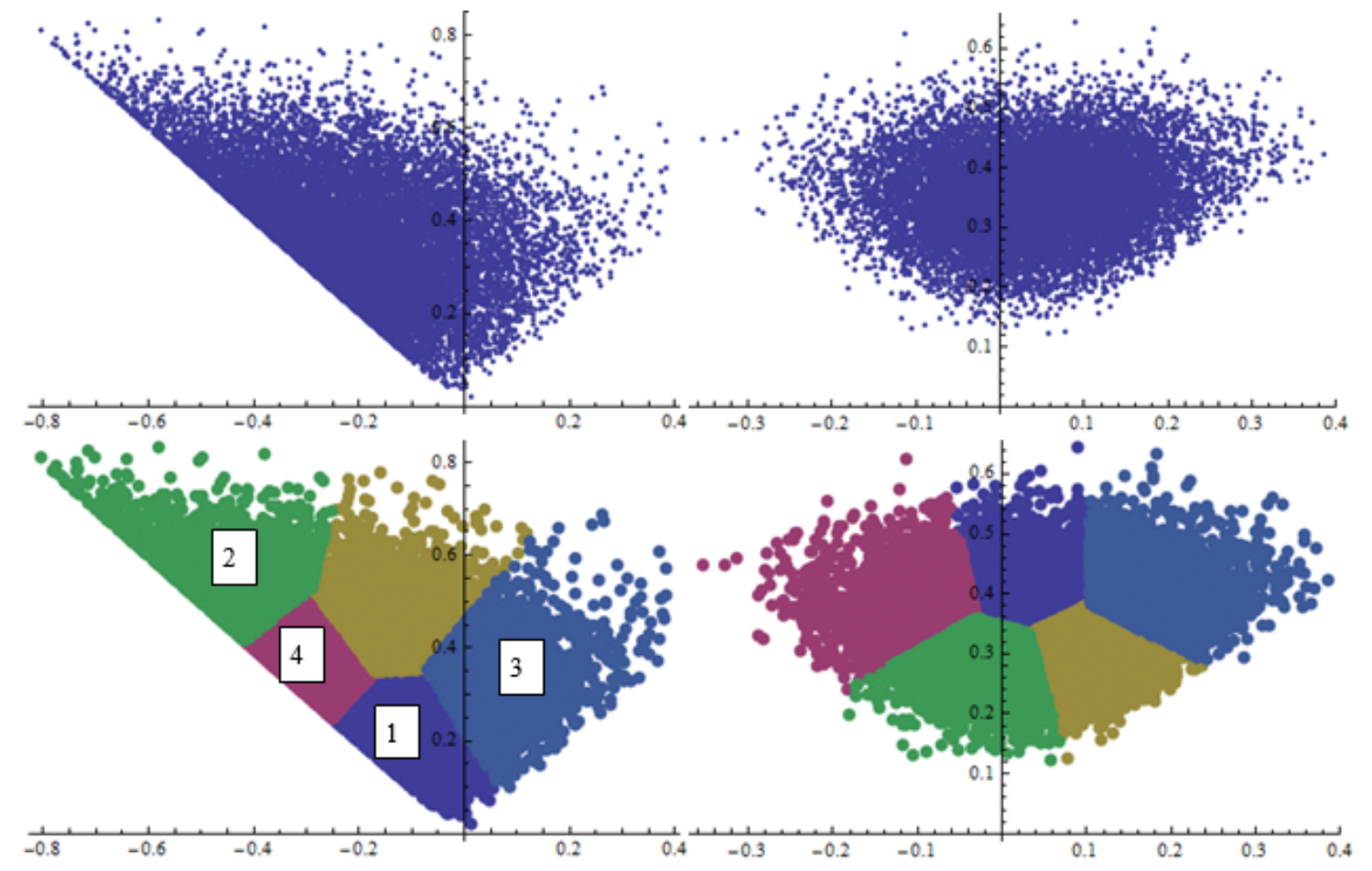

Figure 2. 15000 customers with 5 (left column) and 15 (right column) tasks with 5 clusters.

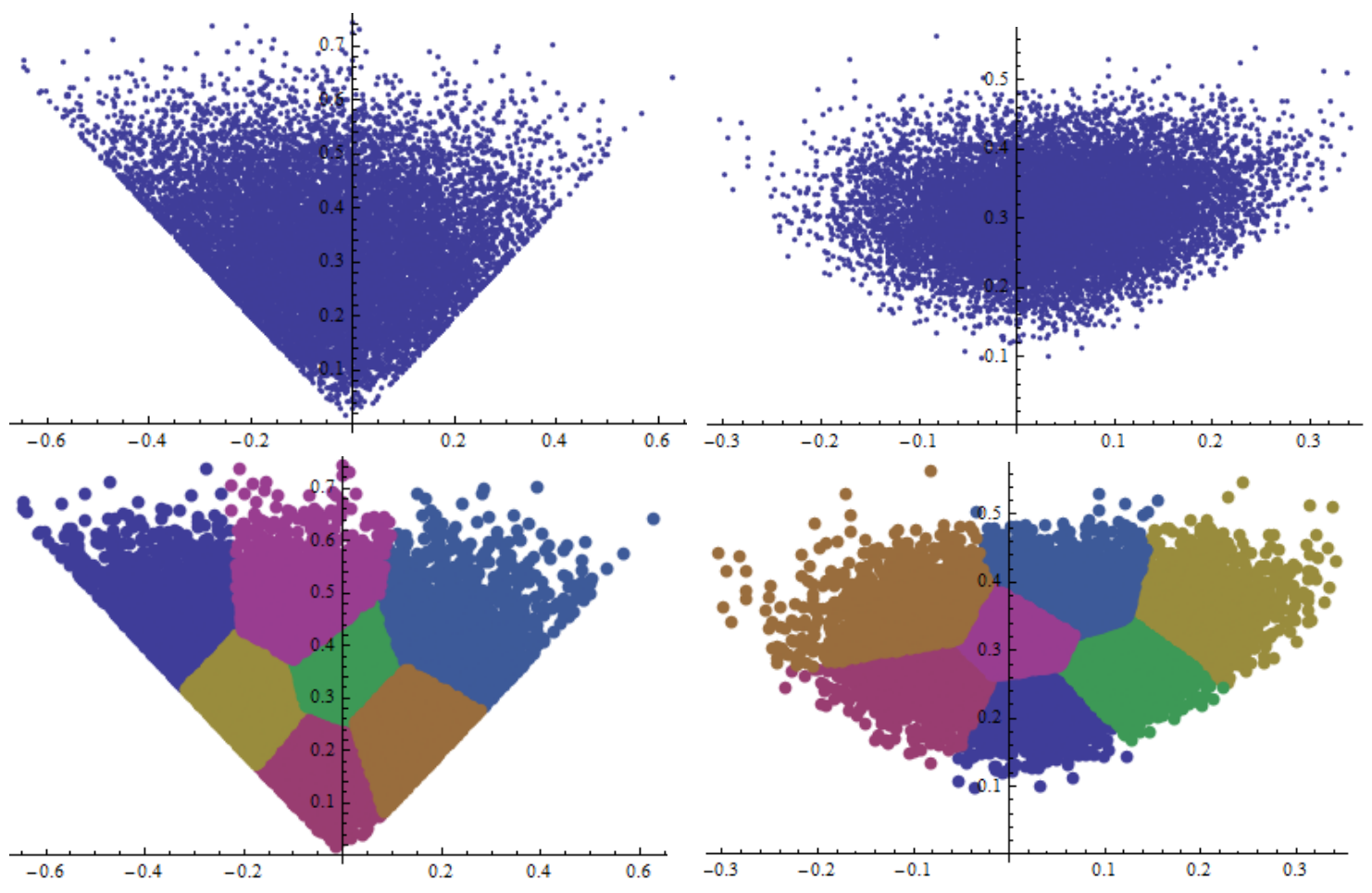


Figure 3. 15000 customers with 5 (left column) and 15 (right column) tasks with 7 clusters.

By applying these ideas the points representing the customer population may look like the first parts of Figures 2 and 3 (simulated by using Netlogo, see Wilensky, 1999, 2002). By applying clustering algorithm based on the Euclidean distance between two customers $b_{j_{1}}$ and $b_{j_{2}}$, i.e.,

$$
d_{j_{1} j_{2}}=\sqrt{\left(x_{j_{1}}-x_{j_{2}}\right)^{2}+\left(y_{j_{1}}-y_{j_{2}}\right)^{2}}
$$

we can identify the corresponding clusters within these populations as given in second parts of the figures. For customers in a given cluster, the producer may apply the most appropriate message addressing the levels of expertise and the attitude of a typical member of the group.

\section{Targeted Messaging}

Let us recall that the main reason for the above clustering is to provide the seller with some additional information on how to design the content of the message describing its product $\boldsymbol{D}$ aiming to reduce the risk of misinforming for a particular group of customers. In Table 1 we outline some suggestions on how to compose the message for the case represented by the lower left picture in Figure 2.

Table 1: Recommendation for customizing messages for clusters of customers as on left column on Figure 2

\begin{tabular}{|c|l|}
\hline Cluster & \multicolumn{1}{c|}{ Recommendation in designing the message } \\
\hline 1 & $\begin{array}{l}\text { For the group of realists with low level of information asymmetry, the one located } \\
\text { around the origin of the two scales, the design of the current message provides ade- } \\
\text { quate information for their correct purchase decision making regarding product } \boldsymbol{D} \text { and } \\
\text { no adjustment of the message is needed. So, for the purposes of this study, this group } \\
\text { of customers is well addressed and could be excluded from further discussion. }\end{array}$ \\
\hline 2 & $\begin{array}{l}\text { To the customers in this group (pessimists with low expertise), the seller must offer } \\
\text { the highest possible warranty of misinforming to allow sufficient training opportunity. }\end{array}$ \\
\hline 3 & $\begin{array}{l}\text { To the customers in this group (optimists with low expertise), the seller must offer the } \\
\text { highest possible warranty of misinforming to allow opportunity to avoid dissatisfac- } \\
\text { tion. }\end{array}$ \\
\hline 4 & $\begin{array}{l}\text { Customers in the violet group possess relatively high expertise but pessimistic atti- } \\
\text { tude. For them the message has to include more technical details regarding the prod- } \\
\text { uct, and good balance between warranty of misinforming and warranty of malfunc- } \\
\text { tioning. }\end{array}$ \\
\hline
\end{tabular}

In general, the following categories of customers can be distinguished, related to the composition of a customized message (see Table 2): 
Table 2. Recommendation for customizing the message for different categories of customers

\begin{tabular}{|c|c|}
\hline $\begin{array}{l}\text { Category of } \\
\text { customers }\end{array}$ & Recommendation in designing the message \\
\hline $\begin{array}{l}\text { Realists ex- } \\
\text { perts } \\
(\mathrm{R} / \mathrm{E})\end{array}$ & $\begin{array}{l}\text { The way expertise and attitude are defined here doesn't allow distinguishing } \\
\text { these two groups, because in the case R/NE pessimistic attitude compensate op- } \\
\text { timistic attitude for some of the product's properties. } \\
\text { The R/E group of customers is well addressed by the current message. }\end{array}$ \\
\hline $\begin{array}{l}\text { Customers } \\
\text { with realistic } \\
\text { behavior } \\
(\mathrm{R} / \mathrm{NE})\end{array}$ & $\begin{array}{l}\text { In case R/NE group is a significant part of the population, the aggregate meas- } \\
\text { ure of attitude is not applicable. This group represents those of the customers } \\
\text { who are not experts, but don't clearly demonstrate pessimist's or optimist's be- } \\
\text { havior. Customers in this group follow a rational approach trying not to overes- } \\
\text { timate or underestimate their expectation toward the product. To attract such } \\
\text { customers the both warranties must be well balanced. }\end{array}$ \\
\hline $\begin{array}{c}\text { Optimists ex- } \\
\text { perts } \\
(\mathrm{O} / \mathrm{E})\end{array}$ & $\begin{array}{l}\text { Those are customers who overestimate the quality/features of the product and } \\
\text { the decision to buy the product could be incorrect. They will realize that the } \\
\text { product is not suitable for their purposes and need time to eventually return it. } \\
\text { This group should be provided with relatively short warranty of misinforming } \\
\text { and the associated expected warranty cost could be relatively high compared to } \\
\text { the same cost for the other customer groups. } \\
\text { In order to reduce the risk of misinforming, the message related to product } D \\
\text { should be modified to use a suitable for product } \boldsymbol{D} \text { professional terminology de- } \\
\text { scribing the detailed specifications and functionalities of the product. The role } \\
\text { of the warranty of misinforming for this group is protective and will be a seller's } \\
\text { tool in neutralizing any customer dissatisfaction. }\end{array}$ \\
\hline $\begin{array}{l}\text { Optimists non- } \\
\text { experts } \\
\text { (O/NE) }\end{array}$ & $\begin{array}{l}\text { These customers overestimate the quality/features of the product and their deci- } \\
\text { sion to buy the product could be incorrect. They will realize that the product is } \\
\text { not suitable for their purposes and need longer (compared to O/E) time to even- } \\
\text { tually return it. } \\
\text { This group should be provided with relatively longer warranty of misinforming } \\
\text { and the associated expected warranty cost could be relatively high compared to } \\
\text { the same cost for the other customer groups. } \\
\text { In order to reduce the risk of misinforming, the message related to product } \boldsymbol{D} \\
\text { should be modified to use non- professional terminology describing the usability } \\
\text { of the product, avoiding "scary" technical terminology. The role of the warranty } \\
\text { of misinforming for this group is also protective and will be seller's tool in neu- } \\
\text { tralizing any customer dissatisfaction due to an incorrect purchase decision. }\end{array}$ \\
\hline
\end{tabular}




\begin{tabular}{|c|l|}
\hline $\begin{array}{c}\text { Category of } \\
\text { customers }\end{array}$ & \multicolumn{1}{c|}{ Recommendation in designing the message } \\
\hline \multirow{2}{*}{$\begin{array}{c}\text { Pessimists } \\
\text { experts }\end{array}$} & $\begin{array}{l}\text { Customers who underestimate the quality/features of the product and therefore } \\
\text { their decision not to buy the product could be incorrect. } \\
\text { This group should be provided with relatively long warranty of misinforming } \\
\text { and the associated expected warranty cost could be relatively low compared to } \\
\text { the same cost for the other customer groups. }\end{array}$ \\
$\begin{array}{c}\text { In order to reduce the risk of misinforming, the message related to product } \boldsymbol{D} \\
\text { should be modified to include all technical specifications, usability/features and } \\
\text { comparison with other similar products available on the marketplace, all given } \\
\text { in suitable technical terms. The role of the warranty of misinforming for this } \\
\text { group is promotional and will be a seller's tool to promote its product and } \\
\text { stimulate the sales volume. }\end{array}$ \\
\hline $\begin{array}{c}\text { Pessimists } \\
\text { non-experts } \\
\text { (P/NE) }\end{array}$ & $\begin{array}{l}\text { Customers who underestimate the quality/features of the product and their deci- } \\
\text { sion not to buy the product could be incorrect. } \\
\text { This group should be provided with relatively long warranty of misinforming } \\
\text { and the associated expected warranty cost could be relatively low compared to } \\
\text { the same cost for the other customer groups. } \\
\text { In order to reduce the risk of misinforming, the message related to product } \boldsymbol{D} \\
\text { should be modified so that technical terminology is avoided but clearly identify- } \\
\text { ing the usability of the product } \boldsymbol{D} \text { and its advantages in comparison with other } \\
\text { similar products available on the marketplace. The role of the warranty of mis- } \\
\text { informing for this group is promotional and will be seller's tool to promote its } \\
\text { product and stimulate the sales volume. }\end{array}$ \\
\hline
\end{tabular}

\section{Directions for Future Research}

Combining approaches and ideas explored by the three areas of research, data analytics, CRM and informing science, which are currently fast developing, allows viewing the problem of serving customers in a new light:

- The development of the data analytics field in the last twenty years has passed through two stages - early results explore historical data to allow better understanding of processes and driving forces; recently the focus moved to support real-time solutions. In this paper we combine exploring historical data to define customer profiles and use it in customizing the message content. The real-time problem is still open.

- CRM evolved dramatically in the last decades by combining opportunities provided by information technologies to customize products offered to customers. Better understanding of customers' behavior allows one to go one step further by customizing also the messages used to approach different groups, or even individual customers.

- The development of informing science foster studies on the multidimensional aspects of the way of acquiring information. One aspect of these studies is elaborating the concept of misinforming and risks associated with effectiveness of conveying messages and factors affecting these risks. Exploring models developed so far allows for customers' portfolio classification with emphasis on their purchase behavior - attitude and expertise, as- 
signing quantity measures on these, and exploring warranty as a tool to address the risk of misinforming.

- The models exploring the aggregated measures of attitude and expertise, developed so far, do not allow distinguishing between R/E and R/NE customers. Developing further metrics, based on the analysis of customers' response to particular parts of the message, and exploring useful relationships between these responses, requires further attention and study.

By exploring simulation techniques (see Niazi \& Hussain, 2009) we demonstrate that the proposed approach is feasible, but there is a still long way to go before reaching some useful practical implication.

\section{Conclusion}

In this paper we presented an approach that explores the some measures of the risk of misinforming, which are based on historical data in the customers' profiles, and uses these measures to cluster/group customers according to their ability to utilize information regarding a product. The composition of the product's promotional message used by the sellers to reach the customers and to facilitate their purchase decision is of high importance due to the growing competition in the marketplace as well as the increasing product complexity. Another aspect of facilitating customers purchase decision is related to the role that the warranty of misinforming could play. Also, the cost associated with the warranty of misinforming could have a strong impact on the producer/customer relationship.

Applying customizing messages to approach different categories of potential customers from Customers Relationship Management (CRM) point of view is of high importance and could benefit both parties - producer and customer - involved in the process. Customers will receive information regarding the product in an easy to understand, interpret, and assess form, which will increase the certainty of their purchase decision. This will prevent the optimists from buying a nonsuitable product and will encourage the pessimists to buy a suitable product. As a result the producers will benefit in increasing the overall number of correct purchase decisions, which will reduce the number of unsatisfied customers and related warranty cost.

From this point of view, message customization via exploring appropriate models related to the risk of misinforming is a win-win strategy in building CRM systems. The availability of datasets related to the customer preferences, stored appropriately for computer-based processing, will allow one not only to define different groups, as presented in the paper, but also to map every customer to the most suitable cluster and even to prepare an individually personalized message.

\section{References}

Akerlof, G. A., (1970). The market for "lemons": Quality uncertainty and the market mechanism. Quarterly Journal of Economics, 84(3), 488-500.

Arrow, K. (2001). Uncertainty and the welfare economics of medical care. Journal of Health Politics, Policy and Law, 26(5), 851-883. (Reprinted from American Economic Review, 1963, 941(947), 965-966.)

Bella, A., Ferri, C., Hernández-Orallo, J., \& Ramírez-Quintana, M. J. (2009). Negotiation with pricedependent probability models. CEUR Workshop Proceedings, 635, pp. 9-20.

Christozov, D., Chukova, S., \& Mateev, P. (2006) A measure of risk caused by information asymmetry in e-commerce. Journal of Issues in Informing Science and Information Technology, 3, 147-158. Retrieved from http://proceedings.informingscience.org/InSITE2006/IISITChri169.pdf 
Christozov, D., Chukova, S., \& Mateev, P. (2007). On the relationship between warranty and the risk of information asymmetry, Journal of Issues in Informing Science and Information Technology, 4, 235 249. Retrieved from http://proceedings.informingscience.org/InSITE2007/IISITv4p235249Chri295.pdf

Christozov, D., Chukova, S., \& Mateev, P. (2009). The risk of misinforming for competing messages. Journal of Issues in Informing Science and Information Technology, 6, 351-364. Retrieved from http://iisit.org/Vol6/IISITv6p351-364Christozov627.pdf

Christozov, D., Chukova, S., \& Mateev, P. (2011). Assessment of risk of misinforming: Dynamic measures. Interdisciplinary Journal of Information, Knowledge, and Management, 6,163-176. Retrieved from http://www.ijikm.org/Volume6/IJIKMv6p163-176Christozov550.pdf

Christozov, D., Chukova, S., \& Mateev, P. (2014). Warranty of misinforming: An overview. Issues in Informing Science and Information Technology, 11, 31-46. Retrieved from http://iisit.org/Vol11/IISITv11p031-046Christozov0470.pdf

González-Prida, V., Gómez, J., Barberá, L., Crespo, A., (2012). The customer relationship in the warranty management of distribution network service providers, 11th International Probabilistic Safety Assessment and Management Conference and the Annual European Safety and Reliability Conference 2012, PSAM11 ESREL 2012, 6, pp. 4460-4470. Available at http://taylor.us.es/sim/documentos/resultados/ 19-Th3-5 _ Gonzalez-Prida.pdf

González Díaz, V, Barberá Martínez, L., Gómez Fernández, J.F., Crespo Márquez, A. (2012). The management of a warranty assistances program: A suggestion as reference framework, Advances in Safety, Reliability and Risk Management, Proceedings of the European Safety and Reliability Conference, ESREL 2011, pp. 2834-2842. Available at http://taylor.us.es/sim/documentos/resultados/Management\%20Warranty\%20ESREL\%202011.pdf

Hsieh, C. T., Lai, F., \& Shi, W. (2006). Information orientation and its impacts on information asymmetry and e-business adoption: Evidence from China's international trading industry. Industrial Management \& Data Systems, 106(6), 825-840.

Huang, Y-S., Lin, Y-J., \& Ho, J-W. (2013). A study on negative binomial inspection for imperfect production systems. Computers and Industrial Engineering, 65(4), 605-613.

Kullback, S., \& Leibler, R. A., (1951). On information and sufficiency. Annals of Mathematical Statistics 22(1), 79-86.

Niazi, M., \& Hussain, A. (2009). Agent-based tools for modeling and simulation of self- organization in peer-to-peer, ad-hoc and other complex networks. IEEE Communications Magazine, 2009

Slovac, P. (1993). Perceived risk, trust, and democracy. Risk Analysis, 13, 675-682.

Wilensky, U. (1999). NetLOGO. Center for Connected Learning and Computer-Cased Modeling, Northwestern University, Evanston, IL. Retrieved November 30, 2014, from http://ccl.northwestern.edu/netlogo/

Wilensky, U. (2002). Netlogo PD N, Person Iterated.

White, M., \& Eiser, R. (2005). Information specificity and hazard risk potential as moderators of trust asymmetry. Risk Analysis, 25(5), 1187-1198. 


\section{Appendix. Notations and Definitions}

\begin{tabular}{|c|c|}
\hline Notation & Definition \\
\hline$D$ & the product \\
\hline$B=\left\{b_{j}\right\}, j=1,2, \ldots, n$ & the set of buyers \\
\hline$A_{j}=\left\{a_{i j}\right\}, i=1,2, \ldots, k_{j}$ & tasks, which the $b_{j}$ needs to solve by using the product \\
\hline$A=\bigcup_{j=1}^{n} A_{j}$ & set of tasks of all buyers \\
\hline$A_{i}^{*}, i=1,2, \ldots, k$ & categories of tasks \\
\hline$n_{i j}$ & the need of $b_{j}$ to solve her task $a_{i j .} 0 \leq n_{i j} \leq 1$ \\
\hline$q_{i j}$ & $\begin{array}{l}\text { degree of acceptance. The minimal quality (a thresh- } \\
\text { old), which the product must possess in order to meet } \\
\text { the client } b_{i} \text { expectations regarding her task } a_{i j} \text {. }\end{array}$ \\
\hline$p_{i}=p\left(A_{i}^{*}\right)$ & $\begin{array}{l}\text { probability that the product will solve problems from } \\
\text { category } A_{i}{ }^{*} \text {. Or the level to which the product } D \text { may } \\
\text { satisfy the buyers needs regarding the tasks from this } \\
\text { category }\end{array}$ \\
\hline$\hat{p}_{i j}=\hat{p}\left(a_{i j}\right)$ & $\begin{array}{l}\text { subjective assessment of the buyer } b_{j} \text { regarding the } \\
\text { probability (level of satisfaction) that the product will } \\
\text { be suitable for solving her task } a_{i j}\end{array}$ \\
\hline$r_{i j}$ & $\begin{array}{l}\text { indicator of the decision correctness } r_{i j}=0 \text { if the decison } \\
\text { is correct; } r_{i j}=1 \text { means wrong decision }\end{array}$ \\
\hline$i a_{i j}=a b s\left(p_{i}-\hat{p}_{i j}\right)$ & measure of information asymmetry \\
\hline$W_{p}(t)$ & warranty policy. $t$-time of the coverage \\
\hline$W_{R}\left(t^{R}\right)$ & $\begin{array}{l}\text { warranty policy regarding risk of malfunctioning (risk } \\
\text { of low reliability) }\end{array}$ \\
\hline$W_{I}\left(t^{I}\right)$ & warranty policy regarding the risk of misinforming \\
\hline$W_{p}=\left\{t^{R}, t^{I}\right\}$ & mixed warranty policy, if $t^{R} \neq 0$ and $t^{I} \neq 0$ \\
\hline$W_{p}\left(t^{R}, 0\right)$ or $W_{p}\left(0, t^{I}\right)$ & pure warranty policies \\
\hline$\mu_{i j}, 0 \leq \mu_{i j} \leq 1$ & $\begin{array}{l}\text { subjective assessment of importance of the misinform- } \\
\text { ing warranty policy for making purchase decision by } b_{j} \\
\text { in respect to task } a_{i j} \text {. }\end{array}$ \\
\hline$B\left(W_{i j}\right)=\mu_{i j} t^{I}+\left(1-\mu_{i j}\right) t^{R}$ & $\begin{array}{l}\text { "balanced" value - represents the effective coverage of } \\
\text { a warranty policy }\end{array}$ \\
\hline$Q\left(W_{i j}\right)=\sqrt{\left(t^{I}-B\left(W_{i j}\right)\right)^{2} \mu_{i j} \cdot+\left(t^{R}-B\left(W_{i j}\right)\right)^{2} \cdot\left(1-\mu_{i j}\right)}$ & $\begin{array}{l}\text { standard deviation - represents the uncertainty associ- } \\
\text { ated with the warranty policy }\end{array}$ \\
\hline$r_{j}^{s}\left(r_{i j}\right)$ & $\begin{array}{l}\text { "simple" measure of the risk in a purchase decision for } \\
b_{j} \text {, depends only on whether the decision is correct or } \\
\text { not }\end{array}$ \\
\hline$r_{j}^{n}\left(r_{i j}, n_{i j}\right)$ & $\begin{array}{l}\text { measure of the risk in a purchase decision for } b_{j} \text {, de- } \\
\text { pends on whether the decision is correct or not; and the } \\
\text { needs }\end{array}$ \\
\hline$r_{j}^{a}\left(r_{i j}, n_{i j}, i a_{i j}\right)$ & $\begin{array}{l}\text { measure of the risk in a purchase decision for } b_{j} \text {, which } \\
\text { incorporates the indicator for correctness of the deci- } \\
\text { sion, the needs and the measure of information asym- } \\
\text { metry }\end{array}$ \\
\hline
\end{tabular}




\begin{tabular}{|l|l|}
\hline$R_{j}^{s}\left(r_{i j}\right)$ & $\begin{array}{l}\text { "simple" measure of the risk in a purchase decision for } \\
\text { group } B, \text { depends only on whether the decision is cor- } \\
\text { rect or not }\end{array}$ \\
\hline$R_{j}^{n}\left(r_{i j}, n_{i j}\right)$ & $\begin{array}{l}\text { Measure of the risk in a purchase decision for group } B, \\
\text { depends on whether the decision is correct or not; and } \\
\text { the needs }\end{array}$ \\
\hline$R_{j}^{a}\left(r_{i j}, n_{i j}, i a_{i j}\right)$ & $\begin{array}{l}\text { measure of the risk in a purchase decision for group } B, \\
\text { which incorporates the indicator for correctness of the } \\
\text { decision, the needs and the measure of information } \\
\text { asymmetry }\end{array}$ \\
\hline$r(t)$ and $R(t)$ & dynamic measures of the risk for $b_{j}$ and for group $B$ \\
\hline
\end{tabular}

\section{Biographies}

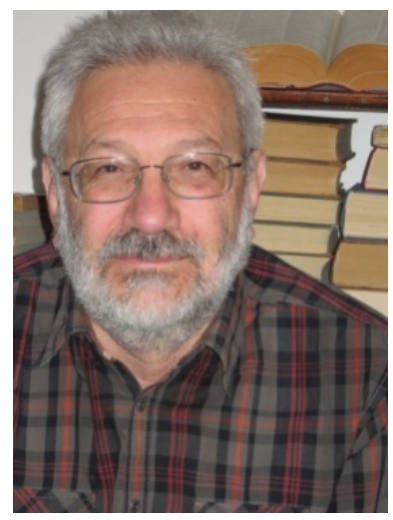

Dimitar Christozov is a Professor of Computer Science at the American University in Bulgaria. He has more than 30 years of experience in areas as computer science, quality management and information systems. He graduated Mathematics from Sofia University "St. Kliment Ohridski" in 1979. He completed his $\mathrm{PhD}$ thesis "Computer Aided Evaluation of Machine Reliability" in 1986. In 2009 he completes his D.Sc. thesis on "Quantitative Measures of Informing Quality". In ICTT "Informa" (1986-1993) Dr. Christozov was involved in establishing the national information network for technology transfer and conducted research in the areas of technologies assessment, integral quality measures and information systems for quality management. In these areas he was recognized as one of the leading experts in Bulgaria. Professor Christozov has more than 100 publications as separate volumes, journal papers and papers in refereed proceedings. He is a founding member and fellow of Informing Science Institute and chair of Bulgarian Informing Science Society; and founding member of the Bulgarian Statistical Society.

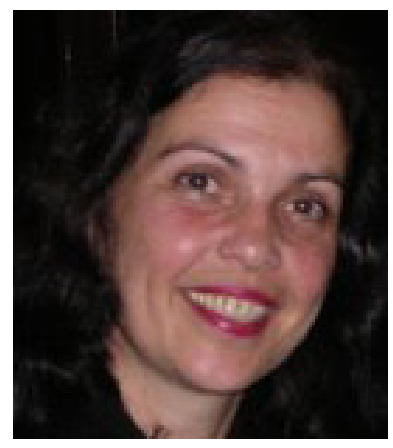

Dr. Stefanka Chukova is a Reader in Operations Research at the School of Mathematics, Statistics and Operation Research, Victoria University of Wellington, Private Bag 600, Wellington, New Zealand, e-mail: schukova@msor.vuw.ac.nz. She has a PhD in Mathematics (concentration in Probability and Statistics) from University of Sofia, Sofia, Bulgaria. Her research interests are in applied stochastic models, warranty analysis, reliability and queuing. She has more than 80 publications and has presented papers at national and international conferences. Stefanka is an elected member of ISI. 


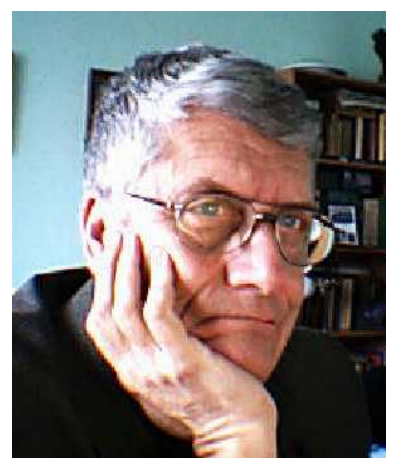

Dr. Plamen Mateev is Associate Professor and Supervisor of Statistical laboratory at the Department "Probability, Operation Research, Statistics", in Sofia University "St.Kliment Ohridski", Faculty of Mathematics and Informatics, Bulgaria, 1164 Sofia, 5, J. Boucher Str., e-mail:pmat@fmi.uni-sofia.bg.

He is a fellow of the Institute of Mathematics and Informatics of the Bulgarian Academy of Sciences.

His MSc in Mathematical Statistics is from Sofia University and his $\mathrm{PhD}$ is from Moscow State University. The research interests are in communication theory, applied statistics, statistical software and applications. He has published nearly 100 papers in scientific journals and conference proceedings. He was the Chair of Bulgarian Statistical Society and a member of ENBIS, IBS and a founding member of the Bulgarian Informing Science Society. 